\title{
Effects of exact and category repetition in true and false recognition memory
}

\author{
STEPHEN A. DEWHURST \\ Lancaster University, Lancaster, England \\ and \\ STEPHEN J. ANDERSON \\ Bristol University, Bristol, England
}

\begin{abstract}
Two experiments used the distinction between remembering and knowing to investigate the effects of exact and category repetition in recognition memory. In Experiment 1, exact repetition enhanced remember responses but had no reliable effect on know responses. In Experiment 2, category repetition enhanced correct know responses but-had no effect on correct remember responses. Category repetition also increased false positive remember and know responses. It is argued that exact repetition influences the recollection component of recognition memory via the creation of multiple episodic traces, each of which is potentially capable of supporting a remember response, whereas category repetition influences the familiarity component of recognition memory by enhancing the fluency with which test items are processed.
\end{abstract}

According to dual-process models of recognition memory, previously studied items can be recognized as old either because they are recollected or because they are associated with feelings of familiarity (e.g., Jacoby, 1988; Jacoby \& Dallas, 1981; Mandler, 1980, 1988). A number of recent studies have attempted to isolate these different components of recognition memory by asking participants in memory experiments to reflect on the experiential nature of their recognition decisions. For example, in the remember-know procedure (Gardiner, 1988; Tulving, 1985), participants are instructed to categorize each item they recognize as either a remember $(R)$ response or a know $(\mathrm{K})$ response. They are asked to make an $\mathrm{R}$ response if they can consciously recollect details of the item's study presentation, and a $\mathrm{K}$ response if the item feels familiar, but they cannot consciously recollect its earlier presentation. The original study by Tulving demonstrated that participants could distinguish these states of awareness, and subsequent research has supported the view that $R$ and $K$ responses reflect qualitatively distinct aspects of recognition memory (see Gardiner \& Java, 1993, and Rajaram \& Roediger, 1997, for reviews).

Tulving (1985) argued that $\mathrm{R}$ and $\mathrm{K}$ responses reflect the states of awareness that characterize retrieval from

\footnotetext{
This research was supported by Grant R000235849 from the Economic and Social Research Council of Great Britain, and we thank the council for its support. We also thank Graham Hitch for helpful comments on an earlier draft of this paper. This research was conducted during S.A.D.'s PhD studentship, supervised by Martin A. Conway, and was supported by a training grant (R000429024739) awarded by the Economic and Social Research Council of Great Britain. Correspondence should be addressed to S. A. Dewhurst, Department of Psychology, Lancaster University, Lancaster LA1 4YF, England (e-mail: s.a. dewhurst@lancaster.ac.uk).
}

episodic and semantic memory, respectively. Subsequent findings, however, were interpreted primarily in terms of a distinction between conceptual and perceptual processes (e.g., Gardiner \& Java, 1990, 1993; Gardiner \& Parkin, 1990; Rajaram, 1993). The pattern of results obtained in early studies supported the view that $R$ responses are sensitive to manipulations that engage conceptual processes whereas $\mathrm{K}$ responses are sensitive primarily to manipulations of perceptual properties of stimuli. For example, $R$ but not $\mathrm{K}$ responses were found to be enhanced by semantic processing (Gardiner, 1988; Rajaram, 1993) and the generation of study items (Gardiner, 1988), and to be reduced by divided attention at encoding (Gardiner \& Parkin, 1990) and the tranquilizer lorezepam (Curran, Gardiner, Java, \& Allen, 1993). In contrast, K but not R responses were found to be enhanced by masked repetition priming (Rajaram, 1993).

More recent studies, however, have suggested that the conceptual-perceptual distinction is too simplistic and that a finer grained analysis is required (e.g., Dewhurst \& Hitch, 1999; Gregg \& Gardiner, 1994). One such analysis was proposed by Rajaram (1996), who argued that the effects so far observed in $R$ and $K$ responses could be explained in terms of a distinctiveness-fluency framework. According to this account, any encoding manipulation that highlights the distinctiveness of study items will subsequently enhance $R$ responses, whereas any operation that increases the fluency with which test items are processed will enhance $\mathrm{K}$ responses. An important feature of this framework is that distinctiveness and fluency are not related directly to conceptual or perceptual processes. $\mathrm{Ra}$ jaram found that some perceptual manipulations (varying the size and orientation of pictures across study and test presentations) influenced $\mathrm{R}$ rather than $\mathrm{K}$ responses. 
These findings indicate that the distinctiveness of a study item can be enhanced by both conceptual and perceptual manipulations, and the effects of both are subsequently observed in $\mathrm{R}$ responses.

Rajaram (1996) suggested that $K$ responses may be sensitive to conceptual as well as perceptual manipulations. Findings reported by Conway, Gardiner, Perfect, Anderson, and Cohen (1997) lend support to this suggestion. They examined the experiential basis of knowledge acquired by psychology undergraduates by asking them to categorize their answers to multiple-choice questions as "remember," "just know," "familiar," or "guess." They found that when information was presented repeatedly in different contexts, the conceptual knowledge acquired was expressed in answers that were assigned predominantly to the "just know" category. Conway et al. argued that the "just know" responses increased because the acquired knowledge had become schematized.

Our main aim in the present study was to conduct a direct test of the view that $K$ responses can be influenced by conceptual as well as perceptual processes. In order to achieve this, we used a conceptual repetition procedure at encoding in which participants saw multiple items from the same semantic categories. There is evidence from a number of studies that conceptual repetition, in which participants see a number of related items, enhances memory. For example, Hintzman (1988) found that presenting multiple items from the same semantic category enhanced the recognition of individual members of the category. In the present study, we used the remember-know procedure to identify the locus of this effect.

The powerful effects on memory of exact repetition have also been widely demonstrated (see Crowder, 1976, Greene, 1992, and Hintzman, 1976, for reviews of repetition effects in memory). For example, Challis and Sidhu (1993) found that exact repetition enhanced performance in recall, cued recall, and recognition memory. Evidence from studies that have used the remember-know procedure suggests that both $R$ and $K$ responses can be influenced by exact repetition, though these studies have produced somewhat inconsistent results. For example, Parkin and Russo (1993) found that $R$ responses were enhanced by repetition when two presentations of an item were spaced (lag6), but that $K$ responses were enhanced when the presentations were massed (lag0). Gardiner, Kaminska, Dixon, and Java (1996) found that the recognition of previously unfamiliar melodies was greater when the melodies were heard four times than when they were heard once. When stimuli consisted of previously unheard classical melodies, the effect of repetition was found only in $\mathrm{R}$ responses. However, when stimuli consisted of previously unheard Polish melodies, the enhancement following repetition was present in both $\mathrm{R}$ and $\mathrm{K}$ responses. Finally, Dewhurst and Hitch (1997) found that three presentations of a word increased $\mathrm{R}$ responses but had no reliable effect on $\mathrm{K}$ responses. These studies indicate that both $\mathrm{R}$ and $\mathrm{K}$ responses are sensitive to the repetition of study items, but the effects so far observed do not show a consistent pattern. A further aim of the present study therefore was to conduct a more detailed analysis of the effects of exact repetition in the recollection and familiarity components of recognition memory.

In order to conduct the two experiments reported here, we first constructed a set of 36 categories of nine members each. Our primary interest was in the effects of category repetition in $\mathrm{K}$ responses. However, since we were also interested in the more general effects of repetition in recognition memory, we began by conducting an exact repetition experiment in which one item from each category was presented repeatedly. Unpublished data collected by Dewhurst and Conway (1993) suggest that multiple exact repetitions enhance $\mathrm{R}$ but not $\mathrm{K}$ responses. Experiment 1 was designed to pursue this finding by presenting to-beremembered items one, four, or eight times. Experiment 2 investigated the effects of conceptual repetition by presenting participants with either one, four, or eight items from the same semantic categories, with each item presented only once. If $\mathrm{K}$ responses are sensitive to manipulations of conceptual properties, then it is possible that they will be enhanced by category repetition.

Recently, Gardiner and his colleagues amended the remember-know procedure by giving participants the option of making a guess response (e.g., Gardiner, Java, \& Richardson-Klavehn, 1996; Gardiner, Ramponi, \& Richardson-Klavehn, 1988). In this modified version, participants are allowed to give guess responses to items that they are unable to categorize as $\mathrm{R}$ or $\mathrm{K}$ responses but that they cannot definitely reject. In one study, Gardiner, Java, and Richardson-Klavehn (1996) examined the influence of a levels-of-processing manipulation in the three response categories and found that guesses produced effects that were inversely related to the effects found in $R$ responses, while $\mathrm{K}$ responses were unaffected by levels of processing. Previous studies (e.g., Dewhurst \& Conway, 1994; Rajaram, 1993) have shown that $\mathrm{K}$ responses are often inversely related to $\mathrm{R}$ responses, an effect that in some cases may be due to changes in participants' response criteria. The findings of Gardiner, Java, and Richardson-Klavehn show that the elimination of guesses from $\mathrm{K}$ responses provides a cleaner measure of familiarity. We therefore included a guess $(\mathrm{G})$ option in addition to the $\mathrm{R}$ and $\mathrm{K}$ response categories.

\section{EXPERIMENT 1}

Experiment 1 investigated the effects of multiple exact repetitions in recognition memory. Participants were presented with one item from each of the 36 categories, and each item was shown either one, four, or eight times. Parkin and Russo (1993) found that the effect of a single repetition on $R$ and $K$ responses is determined by whether the repetition of a target item is massed or spaced. They 
Table 1

Response Probability $(P)$ and Standard Deviations as a Function of Exact Repetition and Response Type for Experiment 1

\begin{tabular}{|c|c|c|c|c|c|c|c|c|c|c|c|c|c|c|}
\hline & \multicolumn{6}{|c|}{ Target } & \multicolumn{8}{|c|}{ Lures* } \\
\hline & \multicolumn{2}{|c|}{1} & \multicolumn{2}{|c|}{4} & \multicolumn{2}{|c|}{8} & \multicolumn{2}{|c|}{1} & \multicolumn{2}{|c|}{4} & \multicolumn{2}{|c|}{8} & \multicolumn{2}{|c|}{$\mathrm{U}$} \\
\hline & $P$ & $S D$ & $P$ & $S D$ & $P$ & $S D$ & $P$ & $S D$ & $P$ & $S D$ & $P$ & $S D$ & $P$ & $S D$ \\
\hline \multicolumn{15}{|c|}{ Spaced repetition } \\
\hline Remember & .45 & .30 & .74 & .19 & .76 & .24 & .00 & .02 & .01 & .04 & .02 & .05 & .01 & .03 \\
\hline Know & .17 & .19 & .13 & .14 & .12 & .20 & .04 & .07 & .06 & .09 & .02 & .05 & .09 & .17 \\
\hline Guess & .06 & .08 & .03 & .06 & .01 & .02 & .04 & .06 & .04 & .07 & .05 & .08 & .07 & .10 \\
\hline \multicolumn{15}{|c|}{ Massed repetition } \\
\hline Remember & .60 & .22 & .68 & .23 & .72 & .26 & .00 & .00 & .01 & .03 & .02 & .06 & .03 & .05 \\
\hline Know & .12 & .12 & .11 & .14 & .10 & .14 & .02 & .04 & .02 & .03 & .02 & .05 & .06 & .10 \\
\hline Guess & .04 & .05 & .03 & .05 & .03 & .05 & .03 & .06 & .04 & .06 & .05 & .05 & .06 & .07 \\
\hline
\end{tabular}

${ }^{*}$ Repetition here refers to the number of presentations of the target item from the same semantic category. U, unrelated.

found that $R$ responses were greater when repetitions were separated by six intervening items (lag6) than when target items were repeated immediately (lag0), while $\mathrm{K}$ responses showed the opposite pattern. It is possible that multiple repetitions of study items will enhance these effects. We therefore included both massed and spaced repetition conditions in Experiment 1, so that repetitions were successive for half of the participants and separated by at least three intervening items for the remaining participants.

\section{Method}

Participants. Forty-eight undergraduate volunteers $(20$ males and 28 females) took part in Experiment $1-24$ in the massed repetition condition and 24 in the spaced repetition condition. Participants were tested individually and were paid for their participation.

Stimuli and Design. Thirty-six categories of nine members each were selected from the Battig and Montague (1969) norms or were created especially for the study. Examples of categories are fruits, colors, parts of the body, and United Kingdom cities. All category members were nouns or proper nouns of high frequency and were selected on the basis that they would be familiar to British participants. ${ }^{1}$ Two items were selected at random from each category, one of which was presented at study and used as the target in the subsequent recognition test, while the other was not presented at study but was used as a lure at test. Items that were targets for half the participants were lures for the remaining participants, and vice versa.

Participants in the massed repetition condition studied the 36 target words, with each item presented either one, four, or eight times in succession. In the spaced repetition condition, repetitions were separated by at least three intervening items. Number of repetitions was a within-subjects factor, so each participant saw 12 items once, 12 items four times, and 12 items eight times. Repetition of items was rotated through three study lists so that each item appeared at each level of repetition for equal numbers of participants. The second set of 36 targets was similarly counterbalanced through a further three study lists. Items that were studied by one group of participants were used as related lures for the remaining group of participants. Study items were presented in uppercase on Apple Macintosh computers. The recognition test consisted of the 36 targets, the 36 related lures, and 36 additional lures from unrelated categories. Unrelated lures were all common nouns and were chosen on the basis that they were not members of the 36 target categories. Test items were presented in a single random order on two sheets of A4 paper, each consisting of three columns of 18 items, with the letters $R, K$, and $G$ printed to the right of each item. The dependent measures were the number of hits and false alarms designated as $R, K$, and $G$ responses.

Procedure. Each word remained on the screen for $1 \mathrm{sec}$ and was replaced after an interval of 1 sec by the next item. Participants were instructed to read the words silently as they appeared on the screen and to bear in mind that they would later be given some form of memory test, the precise nature of which was not specified. Presentation of the 156 trials took approximately 7 min. Participants were then engaged in a nonverbal mental rotation task for $15 \mathrm{~min}$. Following this, they were given the test list and received the following instructions:

These pages contain a set of words, some of which appeared in the list that you read earlier. The letters $R, K$, and $G$ are printed to the right of each item. Your task is to identify those items that appeared in the earlier phase of the experiment. If you believe that an item did not appear in the earlier phase, then leave it and go on to the next item. If you believe that an item did appear in the earlier task, then underline it. In addition, each time you underline an item, I would like you also to circle either $\mathrm{R}, \mathrm{K}$, or $\mathrm{G}$. These stand for remember, know, and guess, and refer to the nature of your conscious experience as you recognize the item. A remember response is one in which you can consciously recollect the appearance of that item some 15 or 20 min ago as a discrete event in your past. You may recall details of the event, such as any thoughts, feelings, or memories you experienced when you saw the item, an association you formed with another item, or some aspect of the item's physical appearance. A know response is one in which you recognize the item because it feels familiar in this context, but you cannot recall its actual occurrence in the earlier phase of the experiment. You recognize the item purely on the basis of a feeling of familiarity. There may be other items that you neither recollect nor recognize on the basis of familiarity, but which you cannot definitely reject. You have the option of making a guess response to these items if you wish. Please think carefully about each item, and make a remember, know, or guess decision for each item that you recognize.

Participants were instructed to give an $R$ response only if they could recollect a specific presentation of the item. All participants were asked to work through the response sheets once, beginning at the top of the left-hand column on each page.

\section{Results and Discussion}

The principal results can be seen in Table 1, which shows the mean proportions of $\mathrm{R}, \mathrm{K}$, and $\mathrm{G}$ responses to targets and lures as a function of number and type of repetitions, plus standard deviations. An alpha level of .05 was used in all statistical analyses. Statistical analyses 
consisted of separate $2 \times 3$ (type of repetition $\times$ number of repetitions) mixed analyses of variance (ANOVAs) on correct $\mathrm{R}, \mathrm{K}$, and $\mathrm{G}$ responses. False alarms were few and will not be considered further.

Correct $\mathrm{R}$ responses increased significantly with repetition $\left[F(2,92)=33.33, M S_{\mathrm{e}}=95.13\right]$, and analysis of simple main effects indicated that this pattern was observed for both spaced repetition $\left[F(2,92)=36.50, M S_{\mathrm{e}}=104.18\right]$ and massed repetition $\left[F(2,92)=4.85, M S_{\mathrm{e}}=13.85\right]$. Planned comparisons showed that in the spaced repetition condition, eight presentations led to reliably more correct $\mathrm{R}$ responses than did a single presentation $(t=7.60)$; the same result held for four presentations $(t=7.18)$. In the massed repetition condition, eight presentations led to reliably more correct $\mathrm{R}$ responses than did a single presentation $(t=3.08)$. Type of repetition was not a significant factor $(F<1)$. The interaction between number and type of repetition was significant $\left[F(2,92)=9.33, M S_{\mathrm{e}}=\right.$ 26.69], indicating that the effect of repetition was greater in the spaced than in the massed condition. A simple main effect of type of repetition indicated that items presented once were associated with more $R$ responses in the massed repetition condition than in the spaced repetition condition $\left[F(1,138)=4.154, M S_{\mathrm{e}}=35.02\right]$.

In contrast to $R$ responses, $K$ responses were not significantly influenced by whether repetitions were spaced or massed $(F<1)$ or by the number of repetitions $\left[F(2,92)=1.79, M S_{\mathrm{e}}=2.84\right]$. Power analysis based on the effect size in $\mathrm{R}$ responses showed a power of greater than .99 to detect a large effect of exact repetition in $\mathrm{K}$ responses. However, correct $\mathrm{G}$ responses decreased as the number of repetitions increased $\left[F(2,92)=3.95, M S_{\mathrm{e}}=\right.$ 1.34]. Analysis of simple main effects indicated that a decrease in $\mathrm{G}$ responses occurred in the spaced repetition condition $\left[F(2,92)=6.92, M S_{\mathrm{e}}=2.35\right]$ but not in the massed repetition condition $(F<1)$. Planned comparisons showed that in the spaced repetition condition, reliably fewer correct guesses were made to items presented eight times than to items presented once $(t=3.68)$.

The results of Experiment 1 show that exact repetition enhances recognition by promoting the conscious recollection of individual instances, since the incidence of $\mathrm{R}$ responses increased with the number of times an item was presented. Type of repetition had no systematic effect on $R$ responses. However, a single presentation in the massed repetition condition led to a much higher incidence of $\mathrm{R}$ responses than did a single presentation in the spaced repetition condition. This somewhat paradoxical finding may be an effect of distinctiveness, since a number of participants in the massed condition claimed that single items "stood out" from repeated items. Single items would clearly not have stood out in this manner when repetitions were spaced.

In contrast to the effects observed in $\mathrm{R}$ responses, $\mathrm{K}$ responses were not reliably affected by repetition, while a reversed effect of spaced repetition was observed in $G$ responses. This reversed effect is consistent with the find- ing by Gardiner, Java, and Richardson-Klavehn (1996) that effects observed in guesses are often inversely related to the effects found in $\mathrm{R}$ responses, while $\mathrm{K}$ responses are unaffected.

\section{EXPERIMENT 2}

In Experiment 2, we investigated the effects of category repetition by presenting participants with one, four, or eight items from the same semantic category. In a similar study, Hintzman (1988) presented participants with either one, three, or five items from various categories and found that the recognition of individual members of a category increased with the number of same-category items seen by the participant. However, the dependent measure used by Hintzman (1988) was overall recognition as a function of repetition. Our aim in this experiment was specifically to investigate the possibility that category repetition would enhance $\mathrm{K}$ responses.

\section{Method}

A second group of 48 student volunteers took part in Experiment 2, consisting of 16 males and 32 females, with 24 in the spaced repetition condition and 24 in the massed repetition condition. The method was the same as that used in Experiment 1 with the exception that participants studied one, four, or eight items from each semantic category, with each item appearing only once. Participants saw a total of 156 words from 36 categories, consisting of one item from each of 12 categories, four items from each of a further 12 categories, and eight items from each of the remaining 12 categories. In order to counterbalance the number of items per category across participants, three study lists were constructed, and the number of items shown per category (one, four, or eight) was rotated through the lists. All three study lists included one target item from each of the 36 categories. A second set of three study lists was also constructed, consisting of the 120 nontarget words plus an alternative set of 36 targets. In the spaced condition, order of presentation was semirandom with the constraint that items from the same category were separated by at least three intervening items from other categories. In the massed condition, items from the same category were presented in successive positions, and the categories were presented in the same random order for each participant.

\section{Results and Discussion}

Mean proportions of hits and false alarms categorized as $R, K$, and $G$ responses are shown in Table 2, together with standard deviations. Statistical analyses consisted of separate $2 \times 3$ (type of repetition $\times$ number of repetitions) ANOVAs on the numbers of correct $R, K$, and $G$ responses. Correct $R$ responses were not reliably influenced by type of repetition or by number of repetitions, with no significant interaction ( $F<1$ in each case). Correct $\mathrm{K}$ responses were not influenced by type of repetition $\left[F(1,46)=1.38, M S_{\mathrm{e}}=5.84\right]$. However, correct $\mathrm{K}$ responses increased significantly with the number of category members presented at encoding $[F(2,92)=11.51$, $\left.M S_{\mathrm{e}}=20.76\right]$, and simple effects showed that this effect was reliably present in both the spaced repetition condition $\left[F(2,92)=4.60, M S_{\mathrm{e}}=8.29\right]$ and the massed repetition 
Table 2

\begin{tabular}{|c|c|c|c|c|c|c|c|c|c|c|c|c|c|c|}
\hline & \multicolumn{6}{|c|}{ Target } & \multicolumn{8}{|c|}{ Lures* } \\
\hline & \multicolumn{2}{|c|}{1} & \multicolumn{2}{|c|}{4} & \multicolumn{2}{|c|}{8} & \multicolumn{2}{|c|}{1} & \multicolumn{2}{|c|}{4} & \multicolumn{2}{|c|}{8} & \multicolumn{2}{|c|}{$\mathrm{U}$} \\
\hline & $P$ & $S D$ & $P$ & $S D$ & $P$ & $S D$ & $P$ & $S D$ & $P$ & $S D$ & $P$ & $S D$ & $P$ & $S D$ \\
\hline \multicolumn{15}{|c|}{ Spaced repetition } \\
\hline Remember & .33 & .22 & .30 & .17 & .31 & .23 & .00 & .02 & .04 & .07 & .06 & .09 & .00 & .05 \\
\hline Know & .18 & .13 & .22 & .13 & .27 & .16 & .07 & .09 & .12 & .13 & .13 & .11 & .02 & .15 \\
\hline Guess & .07 & .08 & .11 & .11 & .08 & .11 & .06 & .11 & .06 & .07 & .14 & .16 & .03 & .18 \\
\hline \multicolumn{15}{|c|}{ Massed repetition } \\
\hline Remember & .36 & .21 & .35 & .22 & .31 & .15 & .05 & .12 & .07 & .13 & .09 & .16 & .01 & .03 \\
\hline Know & .15 & .12 & .16 & .10 & .26 & .16 & .04 & .07 & .14 & .15 & .20 & .13 & .04 & .11 \\
\hline Guess & .05 & .09 & .08 & .15 & .08 & .11 & .05 & .06 & .11 & .11 & .10 & .12 & .04 & .11 \\
\hline
\end{tabular}

* Repetition here refers to the number of presentations of the target item from the same semantic category. U, unrelated.

condition $\left[F(2,92)=7.42, M S_{\mathrm{e}}=13.39\right]$. Planned comparisons showed that in the spaced repetition condition, eight category members led to reliably more correct $\mathrm{K}$ responses than did a single member $(t=3.01)$. In the massed repetition condition, eight category members led to reliably more $\mathrm{K}$ responses than did four members $(t=3.22)$ or a single member $(t=3.44)$. Correct guesses were not reliably influenced by type of repetition $(F<1)$ or by number of repetitions $\left[F(2,92)=2.19, M S_{\mathrm{e}}=2.31, p=.12\right]$. Power analyses based on the effect size in $\mathrm{K}$ responses showed a power of .99 to detect a large effect of category repetition in $R$ and $G$ responses.

Similar analyses on the numbers of false alarms to related lures showed that false recognition errors also increased with the number of category members presented at study. False positive $\mathrm{K}$ responses increased reliably with category repetition $\left[F(2,92)=18.02, M S_{\mathrm{e}}=21.19\right]$, though analysis of simple main effects revealed that this was statistically reliable only in the massed repetition condition $\left[F(2,92)=20.21, M S_{\mathrm{e}}=23.79\right]$. Planned comparisons showed that in the spaced repetition condition, eight category members led to more false alarms than did a single member $(t=2.00)$. In the massed repetition condition, eight category members led to reliably more false alarms than did four members $(t=2.13)$ or a single member $(t=$ 6.25 ), while four items led to more false positive $\mathrm{K}$ responses than did a single member $(t=4.13)$.

Category repetition also produced a significant increase in false positive $\mathrm{G}$ responses $\left[F(2,92)=6.89, M S_{\mathrm{e}}=\right.$ 7.22]. Analysis of simple main effects showed that this pattern was significant in the spaced repetition condition $\left[F(2,92)=7.34, M S_{\mathrm{e}}=7.68\right]$ and close to significance in the massed repetition condition $\left[F(2,92)=3.03, M S_{\mathrm{e}}=\right.$ $3.17, p=.05]$. False positive $\mathrm{R}$ responses also increased with category repetition, as shown by means and standard deviations (Table 2). However, ANOVAs were not appropriate because of the unequal variances in the spaced repetition condition.

The increases in both hits and false alarms suggest that category repetition changed participants' response criteria.
We therefore analyzed $d^{\prime}$ for $\mathrm{R}$ and $\mathrm{K}$ responses. Since $d^{\prime}$ cannot be computed for proportions of 0 or 1 , the proportions were calculated in the manner recommended by Snodgrass and Corwin (1988)-adding a constant of .5 to hit (and false alarm) rates and a constant of 1 to the maximum possible score in each cell. Thus, for example, proportions of hits were calculated by the formula (hits $+.5) /($ maximum +1$)$. Table 3 shows mean $d^{\prime}$ and criterion $(\beta)$ values for each level of repetition. These were analyzed via a series of $2 \times 3$ (type of repetition $\times$ number of repetitions) ANOVAs similar to those carried out on the hits and false alarms. The $d^{\prime}$ values for $\mathrm{R}$ responses decreased significantly as repetitions increased $[F(2,92)=$ $\left.6.21, M S_{\mathrm{e}}=1.47\right]$, and this effect was reliably present in the simple main effects for both spaced repetition $[F(2,92)=$ $\left.2.99, M S_{\mathrm{e}}=.71\right]$ and massed repetition $[F(2,92)=3.36$, $\left.M S_{\mathrm{e}}=.79\right]$. Criterion values for $\mathrm{R}$ responses also decreased as category members increased $\left[F(2,92)=8.73, M S_{\mathrm{e}}=\right.$ $.74]$, and this pattern was again present in both spaced repetition $\left[F(2,92)=5.75, M S_{\mathrm{e}}=.48\right]$ and massed repetition $\left[F(2,92)=3.31, M S_{\mathrm{e}}=.28\right]$. The main effect of number of repetitions in $d^{\prime}$ values for $\mathrm{K}$ responses was close to significance $\left[F(2,92)=2.66, M S_{\mathrm{e}}=.69, p<.08\right]$. However, as can be seen from Table 3 , there was no systematic pattern of effects. Criterion value for $\mathrm{K}$ responses decreased significantly as numbers of category members increased $\left[F(2,92)=22.04, M S_{\mathrm{e}}=2.96\right]$. This pattern was also present in the simple main effects for spaced repe-

Table 3

Values for $d^{\prime}$ and Criterion $(\beta)$ as a Function of Exact Repetition and Response Type for Experiment 2

\begin{tabular}{|c|c|c|c|c|c|c|}
\hline & \multicolumn{3}{|c|}{$d^{\prime}$} & \multicolumn{3}{|c|}{ Criterion $(\beta)$} \\
\hline & 1 & 4 & 8 & 1 & 4 & 8 \\
\hline \multicolumn{7}{|c|}{ Spaced repetition } \\
\hline Remember & 1.26 & 1.00 & .93 & 1.75 & 1.56 & 1.47 \\
\hline Know & .45 & .40 & .54 & 1.38 & 1.19 & 1.13 \\
\hline \multicolumn{7}{|c|}{ Massed repetition } \\
\hline Remember & 1.19 & 1.01 & .83 & 1.54 & 1.44 & 1.33 \\
\hline Know & .54 & .11 & .20 & 1.57 & 1.07 & .86 \\
\hline
\end{tabular}


Table 4

Response Probability $(P)$ and Standard Deviations as a Function of Incidence of $R$ Responses and Category Repetition for Experiment 2

\begin{tabular}{|c|c|c|c|c|c|c|}
\hline & \multicolumn{2}{|c|}{1} & \multicolumn{2}{|c|}{4} & \multicolumn{2}{|c|}{8} \\
\hline & $P$ & $S D$ & $P$ & $S D$ & $P$ & $S D$ \\
\hline \multicolumn{7}{|c|}{ Highest $\mathrm{R}$ responses } \\
\hline Remember & .48 & .19 & .44 & .17 & .44 & .16 \\
\hline Know & .15 & .11 & .18 & .12 & .24 & .16 \\
\hline \multicolumn{7}{|c|}{ Lowest $R$ responses } \\
\hline Remember & .22 & .13 & .20 & .13 & .17 & .09 \\
\hline Know & .17 & .13 & .19 & .12 & .30 & .16 \\
\hline
\end{tabular}

tition $\left[F(2,92)=3.11, M S_{\mathrm{e}}=.42\right]$ and for massed repetition $\left[F(2,92)=23.78, M S_{\mathrm{e}}=3.19\right]$.

As can be seen from Table 2, the rate of correct $R$ responses was relatively low following category repetition. This raises the possibility that the effects of a manipulated variable on $\mathrm{K}$ responses may be influenced by the relative proportions of $R$ and $K$ responses, in that an effect may be observed in $\mathrm{K}$ responses only when the rate of $\mathrm{R}$ responses is low. In order to investigate this possibility, the data from Experiment 2 were divided into two sets according to the numbers of correct $R$ responses made by each participant, and the numbers of correct $K$ responses made by participants from the upper half (i.e., those who made the most correct $R$ responses) were compared with those of the participants from the lower half.

Table 4 shows the proportions of $R$ and $K$ responses for the two groups. The numbers of correct $R$ and $K$ responses were analyzed by separate $2 \times 3$ (high vs. low $\mathrm{R}$ responses $\times$ number of repetitions) ANOVAs in which our primary interest was the simple main effects of repetition in the high and low groups. These revealed no reliable effects of repetition in $\mathrm{R}$ responses for either group. However, the increase in $\mathrm{K}$ responses resulting from category repetition was reliably observed both for participants who made the most $\mathrm{R}$ responses $\left[F(2,92)=3.84, M S_{\mathrm{e}}=\right.$ 6.93] and for those who made the fewest $R$ responses $\left[F(2,92)=8.08, M S_{\mathrm{e}}=14.90\right]$. The effect of category repetition in $\mathrm{K}$ responses was therefore present at both high and low levels of $R$ responses.

The findings of Experiment 2 suggest that category repetition influences recognition memory by enhancing the familiarity of an item, since $\mathrm{K}$ responses to an individual category member increased with the number of items from the same category that were presented at encoding. The enhanced familiarity is indicated by an increase in $\mathrm{K}$ responses to both studied and nonstudied category members. This global enhancement of familiarity within a category is also indicated by the lowering of criterion values for $\mathrm{K}$ responses as category repetition increased. The decreases in $d^{\prime}$ and criterion values in $\mathrm{R}$ responses are presumably due to the fact that false alarms increased while hits were unaffected. This will be considered further in the following section.

\section{GENERAL DISCUSSION}

The present study used the distinction between remembering and knowing (Gardiner, 1988; Tulving, 1985) to investigate the effects of exact and category repetition on subjective experience in recognition memory. In Experiment 1 , exact repetition led to an increase in $\mathrm{R}$ responses, and the magnitude of this effect was greater when repetitions were spaced than when they were massed. In contrast, $\mathrm{K}$ responses were not reliably affected by repetition, while $G$ responses showed a reversed effect of repetition. In Experiment 2, category repetition led to an increase in correct $\mathrm{K}$ responses but had no reliable effect on correct $\mathrm{R}$ responses or on correct guesses. Category repetition also led to an increase in false positive $\mathrm{K}$ responses and, somewhat surprisingly, to an increase in false positive $\mathrm{R}$ responses.

Hintzman (1976) reviewed repetition effects in memory and concluded that the effects of exact repetition are best explained by the creation of multiple episodic traces. The finding from Experiment 1 that exact repetition increased the incidence of $R$ responses is consistent with this account, since $R$ responses are presumed to reflect output from episodic memory (Tulving, 1985). Experiment 1 also showed that the effects of exact repetition are enhanced when presentations are spaced, since the number of $R$ responses increased to a greater degree when repetitions were spaced than when they were massed. This is consistent with findings reported by Parkin and Russo (1993). A simple explanation of this effect is that the spacing of repetitions increases the discriminability of a particular presentation from that of other presentations of the same item, in terms of contextual features such as time of presentation, associations formed with adjacent items, the participant's levels of concentration, and so forth. This is consistent with the proposal by Rajaram (1996) that $R$ responses are enhanced by encoding processes that enhance the distinctiveness of study items.

Unlike $R$ responses, $K$ responses were not reliably influenced by exact repetition. This is in contrast to the findings of Gardiner, Kaminska, et al. (1996) that the repetition of previously unheard Polish melodies enhanced both $R$ and $\mathrm{K}$ responses. However, this difference may be due to the different materials used. The Polish melodies used by Gardiner, Kaminska, et al. were structurally complex and had not previously been heard by the participants. In contrast, the stimuli used in the present study were all common nouns, well known to the participants, and of less complexity than Polish melodies. The findings of Experiment 1 also differ from those of Parkin and Russo (1993), who found that the incidence of $\mathrm{K}$ responses was higher following massed repetition than following spaced repetition. Again, this difference may be due to procedural differences, since type of repetition was a within-subjects factor in Parkin and Russo's study and each word was repeated once only, whereas in the present study type of repetition was a between-subjects factor and multiple repetitions were used. 
It might also be argued that the failure to find an effect of exact repetition in $\mathrm{K}$ responses is due in part to the assumption, inherent in the remember-know procedure, that $\mathrm{R}$ and $\mathrm{K}$ responses are exclusive categories (the analysis of $d^{\prime}$ reported earlier also makes this assumption). Jacoby and his colleagues (e.g., Jacoby, Yonelinas, \& Jennings, 1997; Yonelinas \& Jacoby, 1995) have argued that the relation between recollection and familiarity is one of independence, which allows for the possibility that a recognized item may be both recollected and familiar. According to this view, assessing the effect of a manipulated variable on the familiarity component of recognition memory by measuring the number of $\mathrm{K}$ responses underestimates the effect of that variable on familiarity, since some of the items categorized as $\mathrm{R}$ responses will also be familiar. Yonelinas and Jacoby developed the independence remember-know (IRK) procedure, which allows K responses to be recalculated to fit the independence model. In this procedure, familiarity is calculated by dividing the proportion of $\mathrm{K}$ responses by the opportunity the participant has to make a $\mathrm{K}$ response, giving the formula $\mathrm{F}=$ $\mathrm{K} /(1-\mathrm{R})$.

Since $\mathrm{K}$ responses in Experiment 1 showed no positive effects of exact repetition, we applied the IRK procedure to the data from those experiments (correct $\mathrm{G}$ responses were regarded as misses and as such did not affect the calculation). One problem with this analysis was that 16 participants made correct $\mathrm{R}$ responses to all items in some conditions, with no correct $\mathrm{K}$ responses. The IRK formula thus produced scores of $0 / 0$ in these instances. To overcome this, the data from these participants were ignored and the data from the remaining 32 participants (14 in the spaced repetition condition and 18 in the massed repetition condition) were pooled and analyzed by a one-way (number of repetitions) within-subjects ANOVA. No reliable effect of repetition was observed in the estimates of familiarity $\left[F(2,62)=2.79, M S_{\mathrm{e}}=.16\right]$. Mean estimates of familiarity obtained using the IRK procedure were $.27, .40$, and .34 , for one, four, and eight presentations, respectively.

It might be argued that the failure to find an effect of exact repetition with the IRK procedure was due to the high overall levels of performance, particularly for items presented eight times in the spaced repetition condition. However, we believe it unlikely for other reasons that exact repetition would increase familiarity. The recollection and familiarity processes may be independent, but the states of awareness to which they give rise are by definition exclusive, in that one cannot simultaneously experience recollection and familiarity in the absence of recollection. In these terms, an enhancement of familiarity following exact repetition seems counterintuitive, since feelings of familiarity in the absence of recollection would be more likely to occur for an item presented once than for an item presented four or eight times. The different measures of familiarity obtained by the IRK proce- dure and the remember-know procedure may therefore reflect their different levels of explanation.

The results of Experiment 2 show that category repetition enhanced the familiarity component of recognition memory, since the likelihood of a $K$ response to a single category member increased with the number of items seen from the same category. This effect was observed in both correct and false positive $\mathrm{K}$ responses. One possible explanation of the effects of category repetition in correct and false positive $K$ responses is that both are the result of spreading activation between related items in a semantic network (e.g., Collins \& Loftus, 1975). It is possible that activation within a semantic category increased with the number of items from the category that were presented at study. When a member of a previously seen category was presented at test, the activation that resulted from the preceding encounter with the category enhanced the familiarity of the test item, and this occurred for both studied and nonstudied category members. The more items that are presented from a particular category, the greater the level of activation within that category, and the greater the likelihood that a category member will appear familiar when subsequently presented as a test item. This is supported by studies of semantic priming suggesting that activation spreads to all members of a category (e.g., Neely, Keefe, \& Ross, 1989). The finding that category repetition increased both correct and false positive $\mathrm{K}$ responses suggests that $K$ responses are sensitive to factors that enhance familiarity globally. This is also supported by the lowering of participants' $B$ values for $K$ responses as category repetitions increased.

The finding that $\mathrm{K}$ responses were enhanced by category repetition presents a problem for the view that such responses reflect perceptual processes, since the relation between members of the same semantic category is conceptual rather than perceptual. This finding is, however, consistent with the fluency component of Rajaram's (1996) distinctiveness-fluency framework. It is possible that the increase in activation following category repetition enhances the fluency with which members of the category are processed when subsequently presented in a test of recognition memory, thus increasing the likelihood of a $\mathrm{K}$ response. The results of Experiment 2 in the present study are therefore complementary to those of Rajaram in showing that distinctiveness and fluency are orthogonal to conceptual and perceptual processes. Rajaram found that some perceptual manipulations (varying the size and orientation of pictures across study and test presentations) influenced $R$ rather than $K$ responses. The results of Experiment 2 in the present study indicate that $K$ responses can be influenced by a conceptual manipulation. Thus, $\mathrm{K}$ responses can be influenced by both conceptual and perceptual processes, as can $\mathrm{R}$ responses.

One unexpected finding from Experiment 2 was that false positive $\mathrm{R}$ responses increased with category repetition. In most previous studies that have used the 
remember-know procedure, the rate of false positive $R$ responses has been extremely low and not significantly influenced by encoding manipulations (e.g., Dewhurst \& Conway, 1994; Gardiner \& Java, 1990; Rajaram, 1993). The increase in false positive $\mathrm{R}$ responses with category repetition is, however, consistent with data reported by Roediger and McDermott (1995). They used a procedure developed by Deese (1959) in which participants studied lists of words consisting of associates of critical (nonpresented) words. Roediger and McDermott obtained the false recall effect reported by Deese, and in addition found a high incidence of false alarms for the nonstudied items in a subsequent recognition test, particularly when these had been falsely recalled in the previous phase of the experiment. Roediger and McDermott interpreted the false alarms as errors of source monitoring (Johnson, Hashtroudi, \& Lindsay, 1993), in that participants may have implicitly generated the word at study and confused this with actually hearing it. The same explanation can account for the present results. Indeed, a number of participants in Experiment 2 reported that they had anticipated items in this manner.

To summarize, the present findings show that exact repetition influences recognition performance by enhancing the recollection component of recognition memory, as measured by $\mathrm{R}$ responses. In contrast, category repetition influences recognition memory by enhancing the familiarity of both studied and nonstudied category members, possibly via spreading activation within a semantic network, resulting in increases in both correct and false positive $\mathrm{K}$ responses. Category repetition also leads to the false recollection of nonstudied category members. The findings of Experiment 1 suggest that exact repetition leads to the creation of multiple episodic traces, each of which is potentially capable of supporting an $R$ response. The effects of category repetition in $\mathrm{K}$ responses in Experiment 2 cannot be accounted for by the view that $\mathrm{K}$ responses reflect perceptual processes. These findings are, however, consistent with the view that $\mathrm{K}$ responses reflect the fluency with which test items are processed and indicate that fluency of processing can be enhanced by conceptual as well as by perceptual operations.

\section{REFERENCES}

Battig, W. F., \& Montague, W. E. (1969). Category norms for verbal items in 56 categories: A replication and extension of the Connecticut category norms. Journal of Experimental Psychology Monograph, 80, (3, Pt. 2).

Challis, B. H., \& Sidhu, R. (1993). Dissociative effect of massed repetition on implicit and explicit measures of memory. Journal of Experimental Psychology: Learning, Memory, \& Cognition, 19, 115 127.

Collins, A. M., \& LoFrus, E. F. (1975). A spreading-activation theory of semantic processing. Psychological Review, 82, 407-428.

Conway, M. A., Gardiner, J. M., Perfect, T. J., Anderson, S. J., \& CoHEN, G. (1997). Changes in memory awareness during learning: The acquisition of knowledge by psychology undergraduates. Journal of Experimental Psychology: General, 126, 393-413.
CROWDER, R. G. (1976). Principles of learning and memory. Hillsdale, NJ: Erlbaum.

Curran, H. V., Gardiner, J. M., Java, R. I., \& Allen, D. (1993). Effects of lorezepam on recollective experience in recognition memory. Psychopharmacology, 40, 309-313.

DEESE, J. (1959). On the prediction of occurrence of particular verbal intrusions in immediate recall. Journal of Experimental Psychology, $58,17-22$.

Dewhurst, S. A., \& Conway, M. A. (1993). [Direct repetition increases $R$ but not $K$ responses]. Unpublished raw data.

Dewhurst, S. A., \& ConWAY, M. A. (1994). Pictures, images, and recollective experience. Journal of Experimental Psychology: Learning, Memory, \& Cognition, 20, 1088-1098.

Dewhurst, S. A., \& HiTCH, G. J. (1997). Illusions of familiarity caused by cohort activation. Psychonomic Bulletin \& Review, 4, 566-571.

Dewhurst, S. A., \& Hitch, G. J. (1999). Cognitive effort and recollective experience in recognition memory. Memory, 7, 129-146.

GARDINER, J. M. (1988). Functional aspects of recollective experience. Memory \& Cognition, 16, 309-313.

GARDINER, J. M., \& JAVA, R. I. (1990). Recollective experience in word and nonword recognition. Memory \& Cognition, 18, 23-30.

GARDINER, J. M., \& JAVA, R. I. (1993). Recognizing and remembering. In A. F. Collins, S. E. Gathercole, M. A. Conway, \& P. E. Morris (Eds.), Theories of memory (pp. 163-188). Hillsdale, NJ: Erlbaum.

GARDINER, J. M., JAVA, R. I., \& RICHARDSON-KLAVEHN, A. (1996). How level of processing really influences awareness in recognition memory. Canadian Journal of Experimental Psychology, 50, 114-122.

GARDINER, J. M., KAMINSKA, Z., DixoN, M., \& JAVA, R. I. (1996). Repetition of previously novel melodies sometimes increases both remember and know responses in recognition memory. Psychonomic Bulletin \& Review, 3, 366-371.

GARDINER, J. M., \& PARKIN, A. J. (1990). Attention and recollective experience in recognition memory. Memory \& Cognition, 18, 579-583.

GARDINER, J. M., RAMPONI, C., \& RichaRdSON-KLAVEHN, A. (1998). Experiences of remembering, knowing, and guessing. Consciousness \& Cognition, 7, 1-26.

GreEne, R. L. (1992). Human memory: Paradigms and paradoxes. Hillsdale, NJ: Erlbaum.

GREGG, V. H., \& GaRDINER, J. M. (1994). Recognition memory and awareness: A large effect of study-test modalities on 'know' responses following a highly perceptual orienting task. European Journal of Cognitive Psychology, 6, 131-147.

HintzMAN, D. L. (1976). Repetition and memory. In G. H. Bower (Ed.), The psychology of learning and motivation (Vol. 10, pp. 47-91). New York: Academic Press.

HintzMAN, D. L. (1988). Judgments of frequency and recognition memory in a multiple-trace memory model. Psychological Review, 95, 528-551.

JACOBY, L. L. (1988). Memory observed and memory unobserved. In U. Neisser \& E. Winograd (Eds.), Remembering reconsidered: Ecological and traditional approaches to the study of memory (pp. 145-177). New York: Cambridge University Press.

JACOBY, L. L., \& DALLAS, M. (1981). On the relationship between autobiographical memory and perceptual learning. Journal of Experimental Psychology: General, 110, 306-340.

JACOBY, L. L., Yonelinas, A. P., \& Jennings, J. M. (1997). The relation between conscious and unconscious (automatic) influences: A declaration of independence. In J. Cohen \& J. W. Schooler (Eds.), Scientific approaches to the question of consciousness (pp. 13-47). Mahwah, NJ: Erlbaum.

Johnson, M. K., HAShTROUdi, S., \& LindSAY, D. S. (1993). Source monitoring. Psychological Bulletin, 114, 3-28.

MANDLER, G. (1980). Recognizing: The judgment of previous occurrence. Psychological Review, 87, 252-271.

MANDLER, G. (1988). Memory: Conscious and unconscious. In P. R. Solomon, G. R. Goethals, C. M. Kelley, \& B. R. Stephens (Eds.), Memory: Interdisciplinary approaches (pp. 84-106). New York: Springer-Verlag.

NeELY, J. H., KeEFE, D. E., \& Ross, K. (1989). Semantic priming in the 
lexical decision task: Roles of prospective prime-generated expectancies and retrospective semantic matching. Journal of Experimental Psychology: Learning, Memory, \& Cognition, 15, 1003-1019.

PARKIN, A. J., \& Russo, R. (1993). On the origin of functional differences in recollective experience. Memory, 1, 231-237.

RaJARaM, S. (1993). Remembering and knowing: Two means of access to the personal past. Memory \& Cognition, 21, 89-102.

RaJARAM, S. (1996). Perceptual effects on remembering: Recollective processes in picture recognition memory. Journal of Experimental Psychology: Learning, Memory, \& Cognition, 22, 365-377.

RAJARAM, S., \& RoEDIGER, H. L., III (1997). Remembering and knowing as states of consciousness during retrieval. In J. Cohen \& J. W. Schooler (Eds.), Scientific approaches to the question of consciousness (pp. 213-214). Mahwah, NJ: Erlbaum.

Roediger, H. L., III, \& MCDermott, K. B. (1995). Creating false memories: Remembering words not presented in lists. Journal of Experimental Psychology: Learning, Memory, \& Cognition, 21, 803814.

SNODGRass, J. G., \& CoRwin, J. (1988). Pragmatics of measuring recognition memory: Applications to dementia and amnesia. Journal of Experimental Psychology: General, 117, 34-50.
Tulving, E. (1985). Memory and consciousness. Canadian Psychologist, 26, 1-12.

Yonelinas, A. P., \& JACOBY, L. L. (1995). The relation between remembering and knowing as bases for recognition: Effects of size congruency. Journal of Memory \& Language, 34, 622-643.

\section{NOTE}

1. Most category members were named by at least 10 of Battig and Montague's (1969) respondents. However, exceptions such as cider (alcoholic drink) and ambulance (vehicle) were selected on the grounds that they were more familiar to British students than the items listed by American students in Battig and Montague's study. Members of categories not included in the Battig and Montague norms (e.g., United Kingdom cities) were also chosen on the basis of their familiarity to British students.

(Manuscript received February 11, 1998; revision accepted for publication May 27, 1998) 